\title{
Otomatisasi Sistem Fertigasi Tetes untuk Tanaman Berbasis Mikrokontroler
}

\author{
Iswadi Hasyim Rosma*, Dian Yayan Sukma, dan Ikhram Minata Solihin \\ Jurusan Teknik Elektro, Fakultas Teknik, Universitas Riau \\ Kampus Bina Widya, Jl. HR Soebrantas Km 12,5, Pekanbaru, Riau, 28293, Indonesia \\ *Corresponding author.Email: iswadi.hr@lecturer.unri.ac.id
}

\begin{abstract}
The process of manual fertilization and irrigation of plants has disadvantages such as it requires human labor and is inefficient in the use of fertilizers and water sources. Therefore, the purpose of this research is to design and develop an automatic fertigation system. The method used in this research is a drip fertigation technique where the fertigation liquid that has been stirred is placed in a tank with $100 \mathrm{~cm}$ height from ground. With the gravitational force, the fertigation liquid is distributed through pipes, hoses and emitters around the plant. While the control system and automation of fertigation distribution to plants is carried out based on a microcontroller that need the condition of soil moisture values around the plant. If the watering time and humidity values are met, the electronic valve will open so that the fertigation liquid flows from the tank to the plants. Furthermore, in this study the tests were carried out to determine the uniformity coefficient and debit of drip fertigation. From the results, it shows that the emitter's debit influenced by the liquid level in the tank. The uniformity coefficient obtained in the two tests is greater than $90 \%$. From the two tests carried out from the moisture sensor 1 and 2, it shows the mean percentage error for both sensor is less than 1.7\%, while the percentage error of soil moisture sensor 1 is $1.6 \%$ and the percentage error of soil moisture sensor 2 is $1 \%$, respectively. Meanwhile, from the ultrasonic sensor testing it was obtained $0 \%$ of error. It also shows from the testing conducted that the fertigation system works very well and successfully.
\end{abstract}

Keywords - fertilization, fertigation, drip irrigation, microcontroller, uniformity coefficient, soil moisture sensor

\begin{abstract}
Abstrak- Proses pemupukan (fertilisasi) dan pengairan (irigasi) tanaman secara manual memiliki kelemahan yaitu membutuhkan tenaga manusia dan tidak efisien dalam penggunaan pupuk dan sumber air. Oleh sebab itu, tujuan penelitian ini adalah untuk merancang dan membangun sistem fertigasi otomatis. Metode yang digunakan adalah teknik fertigasi tetes di mana cairan fertigasi yang sudah diaduk ditempatkan pada sebuah tangki dengan ketinggian $100 \mathrm{~cm}$ dari permukaan tanah. Dengan gaya grafitasi dari tangki tersebut, cairan fertigasi disalurkan melalui pipa, selang dan emitter ke tanah disekitar tanaman. Sedangkan sistem kendali dan otomatisasi penyaluran fertigasi ke tanaman dilakukan berbasis mikrokontroler yang membaca nilai kelembaban tanah yang ada di sekitar tanaman. Jika waktu penyiraman dan nilai kelembaban terpenuhi, maka katup elektronik akan membuka sehingga cairan fertigasi dialirkan dari tangki menuju tanaman. Selanjutnya pada penelitian ini telah dilakukan pengujian untuk mengetahui debit dan koefisien keseragaman fertigasi tetes. Dari hasil pengujian diperoleh bahwa debit pada emitter dipengaruhi oleh tinggi cairan di dalam tangki. Koefisien keseragaman yang didapatkan pada dua pengujian tersebut lebih besar dari 90\%. Pada pengujian 2 buah sensor kelembaban tanah yang digunakan, didapatkan hasil persentase kesalahan rata-rata kurang dari $1,7 \%$, di mana didapatkan hasil kesalahan rata-rata pada sensor kelembaban tanah 1 yaitu 1,6\% dan kesalahan rata-rata untuk sensor kelembaban tanah 2 yaitu $1 \%$. Sementara itu untuk pengujian sensor ultrasonik didapatkan hasil sensor yang diuji memiliki persentase kesalahan yaitu $0 \%$. Dari hasil pengujian sistem fertigasi yang telah dibangun didapatkan bahwa sistem bekerja dengan sangat baik.
\end{abstract}

Kata kunci- pemupukan, fertigasi, fertigasi tetes, mikrokontroler, koefisien keseragaman, sensor kelembaban tanah

\section{PENDAhUluan}

Proses penyiraman dan pemupukan tanaman merupakan salah satu faktor penting yang mempengaruhi pertumbuhan dan perkembangan suatu tanaman. Air dan unsur hara berperan sebagai faktor eksternal dalam proses pertumbuhan, perkembangan, dan produktifitas tanaman. Namun, jika pemupukan dilakukan tidak sesuai dengan kebutuhan tanaman dan tidak tepat pada waktu yang telah ditentukan, maka akan menurunkan produktivitas tanaman tersebut. Oleh karena itu diperlukan sebuah sistem untuk mengendalikan pendistribusian larutan pupuk cair dengan air (fertigasi) sehingga dapat membantu petani dalam melakukan pemupukan secara efisien dan hemat tenaga manusia [1].

Untuk mengefisiensikan penggunaan cairan fertigasi yang digunakan, maka dapat dilakukan dengan menggunakan metode fertigasi otomatis. Pemberian cairan fertigasi yang efisien salah satunya adalah metode tetes, yaitu sistem pemberian cairan fertigasi yang bertekanan rendah melalui pipa distribusi dari tabung secara perlahan di dasar setiap tanaman atau tanah di sekitarnya dengan menggunakan emitter atau penetes. Emitter adalah suatu komponen berupa

Received 10 July 2021, Accepted 27 September 2021, Published 4 October 2021.

DOI: https://doi.org/10.15294/jte.v13i1.31123 
penetes pada sistem fertigasi tetes yang digunakan untuk meneteskan cairan fertigasi ke setiap tanaman [2] - [4].

Penerapan fertigasi berbasis mikrokontroler dapat memudahkan petani untuk menjalankan fungsi pendistribusian cairan fertigasi secara otomatis [1]. Sistem fertigasi dibangun menggunakan mikrokontroler yang didukung beberapa komponen lainnya seperti sensor kelembaban tanah untuk mendeteksi kelembaban tanah, Real Time Clock (RTC) sebagai sensor waktu yang akan menunjukkan waktu yang sesuai untuk melakukan pemupukan, sensor ultrasonik sebagai sensor ketinggian cairan fertigasi di dalam tangki, Liquid Crystal Display (LCD) sebagai interface antara pengguna dengan alat, dan water valve sebagai keran otomatis.

Pada penelitian sebelumnya telah dilakukan pengujian kinerja sistem kontrol fertigasi dengan metode tetes untuk tanaman bayam yang menunjukkan kinerja yang baik [5]. Sedangkan pada penelitian [6] telah dilakukan perancangan dan pembangunan sistem fertigasi dengan menggunakan venturimeter. Rancangan alat fertigasi menggunakan pipa PVC dan dua venturimeter dipasang paralel, dengan ukuran satu inci. Hasil dari penelitian [7] menunjukkan keberhasilan teknologi sprinkle otomatis berbasis Arduino Uno dan sensor kelembaban tanah YL-69. Sedangkan pada penelitian [4] menunjukkan kinerja irigasi tetes untuk tanaman cabai pada greenhouse yang mampu menghasilkan koefisien keseragaman irigasi tetes sebesar 76,97\%. Sehingga penelitian yang dilakukan adalah membangun suatu sistem fertigasi tetes dengan menggunakan sistem kendali berbasis mikrokontroler yang menggunakan sensor ultrasonik dan sensor kelembaban tanah sebagai tambahan indikator dalam melakukan pemupukan dan mendapatkan hasil koefisien fertigasi tetes yang dibangun dengan kategori yang sangat baik sebagai tolak ukur dalam kelayakan suatu sistem fertigasi tetes yang dibangun

Adapun tujuan dari penelitian yang dilakukan adalah merancang dan membangun, serta menguji kinerja sistem fertigasi untuk tanaman di mana pada proses pengujiannya menggunakan tanaman tomat. Ada dua komponen utama yang dirancang dan dibangun, yaitu sistem distribusi berbasis fertigasi tetes dan sistem kendali berbasis mikrokontroler. Selain itu, artikel ini juga membahas tentang kinerja sistem fertigasi tersebut seperti: debit emitter, koefisien irigasi tetes, analisis kinerja sensor ultrasonik, dan analisis kinerja sensor kelembaban tanah yang selanjutnya akan dibahas dalam bagian hasil dan pembahasan artikel ini.

Sistematika artikel ini terdiri dari empat sub bagian utama. Bagian II membahas tentang metode yang berisikan perancangan sistem dan kendali fertigasi tetes, cara menentukan debit emitter, besaran koefisien keseragaman, dan kalibrasi sensor kelembaban tanah. Hasil pengujian dan pembahasan disajikan secara mendalam pada bagian III. Sedangkan bagian IV dari artikel ini menyimpulkan hasil yang dicapai dari penelitian ini secara komprehensif.

\section{METODE}

Ada 6 tahapan yang telah dilakukan agar tujuan dari penelitian yang dilakukan dapat dicapai dengan baik. Keenam tahapan tersebut dijelaskan secara rinci pada sub bagian A sampai dengan sub bagian $\mathrm{F}$.

\section{A. Diagram Blok Sistem Fertigasi Tetes}

Sebelum melakukan perancangan terhadap sistem fertigasi tetes dan sistem kendali fertigasi tetes maka perlu untuk memahami bagian utama pada pembuatan sistem seperti yang ditunjukkan diagram blok pada Gambar 1 .

Pada Gambar 1 sistem menggunakan listrik tegangan 220 VAC sebagai sumber sistem kelistrikan alat, namun untuk komponen elektronika yang memerlukan tegangan rendah arus searah, tegangan 220 VAC akan diturunkan ke tegangan rendah VDC sesuai dengan tegangan yang dibutuhkan komponen dengan menggunakan power suplai. Untuk water valve merupakan komponen elektronika yang memerlukan tegangan kerja 220VAC, sehingga water valve mendapatkan suplai langsung 220VAC. Proses pengendalian komponen elektronik baik input maupun output dilakukan oleh mikrokontroler Arduino Uno. Komponen input yang dikendalikan oleh Arduino Uno yaitu RTC sebagai komponen input untuk membaca waktu, sensor ultrasonik sebagai komponen input untuk membaca jarak cairan fertigasi pada tangki, dan sensor kelembaban tanah sebagai komponen input untuk untuk membaca kelembaban tanah disekitar tanaman. Untuk komponen output yang dikendalikan oleh Arduino Uno antara lain seperti LCD sebagai penampil data pembacaan komponen input, Solid State Relay (SSR) sebagai pengendali water valve, dan water valve sebagai kran otomatis. Beberapa komponen yang digunakan sebagai pembaca data harus terhubung secara langsung ke tempat di mana pembacaan data dilakukan seperti sensor ultrasonik yang diletakkan di atas tangki dan sensor kelembaban tanah yang harus diletakkan di tanah sekitar tanaman. Untuk pendistribusian cairan fertigasi dikontrol oleh water valve sebagai kran otomatis, di mana cairan fertigasi yang berada pada tangki akan melewati water valve terlebih dahulu yang selanjutnya akan diteruskan ke tanah disekitar tanaman.

\section{B. Perancangan Sistem Fertigasi Tetes}

Perancangan sistem fertigasi tetes meliputi perancangan kerangka dudukan tangki suplai, perancangan panjang pipapipa yang digunakan, luas penampang pipa yang digunakan, dan luas penampang selang yang digunakan. Gambar 2 menunjukkan dimensi perancangan sistem fertigasi tetes yang dibahas pada penelitian ini.

Rata-rata kebutuhan air pada tanaman tomat di daerah tropis adalah antara $300 \mathrm{ml}$ sampai dengan $400 \mathrm{ml}$ perhari pertanaman tomat [8]. Jika dalam kondisi kemarau maka tingkat kelembaban tanah sangat rendah sehingga kebutuhan air pada tanaman tomat dapat lebih dari pada $400 \mathrm{ml}$.

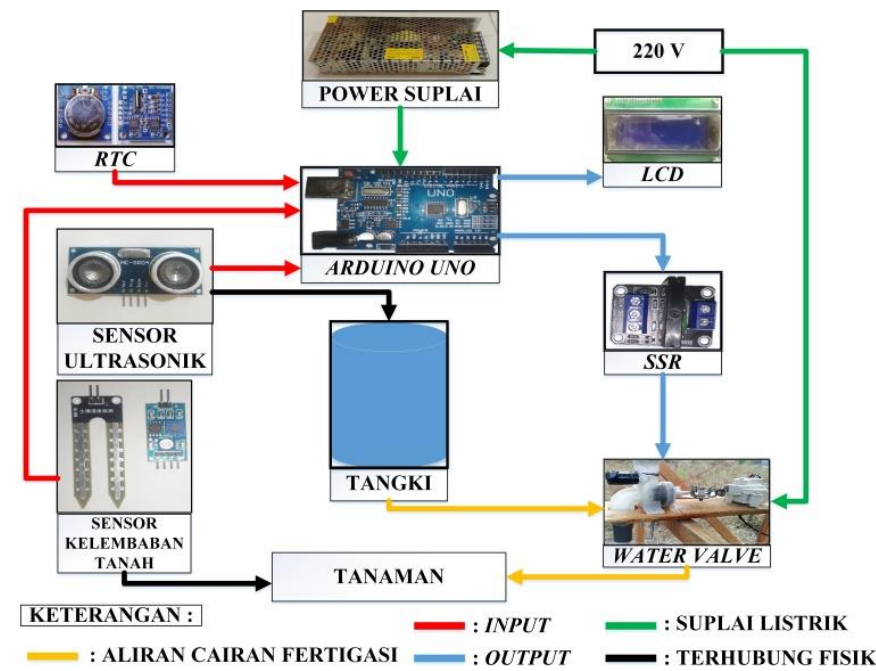

Gambar 1. Diagram blok sistem fertigasi tetes 


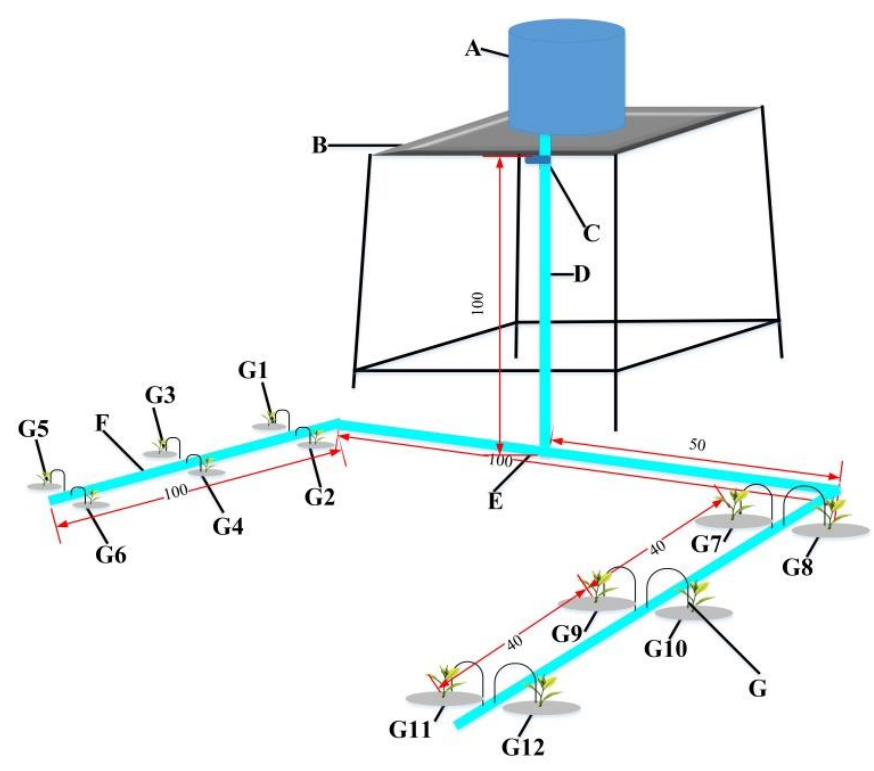

Gambar 2. Dimensi perancangan sistem fertigasi tetes

Tangki (A) dibuat menggunakan bahan plat besi dengan ukuran diameter tangki $21 \mathrm{~cm}$ dan tinggi tangki $32 \mathrm{~cm}$ dengan indikasi ketersediaan suplai pada tangki di ketinggian sama dengan atau lebih dari $11 \mathrm{~cm}$. Tangki diletakkan di atas tower (B) yang dibuat dengan menggunakan bahan kayu dengan tinggi $100 \mathrm{~cm}$ dari permukaan tanah. Dengan ukuran tangki (A) yang kecil maka pemupukan untuk tanaman tomat dengan cairan fertigasi dapat dilakukan hanya untuk sekali pemupukan dalam waktu 14 hari sekali.

Sebuah katup elektronik (C) dipasangkan tepat di bawah tangki suplai sebagai keran otomatis untuk mengalirkan dan menutup aliran suplai dari tangki ke tanaman dan sebagai penghubung antara tangki (A) pipa utama (D). Pipa utama (D) ini dibangun dengan menggunakan pipa jenis PVC dengan panjang $100 \mathrm{~cm}$ dengan ukuran $1 / 2$ inci.

Pipa manifold (E) disebut juga sebagai pipa distribusi di mana fungsi dari pipa ini adalah sebagai pendistribusi suplai dari pipa utama (D) ke pipa lateral (F). Pada penelitian ini pipa manifold yang dibangun memiliki panjang $2 \times 50 \mathrm{~cm}$, dan pipa yang digunakan adalah pipa PVC dengan ukuran $1 / 2$ inci.

Pipa lateral (F) memiliki dua bagian, masing-masing pipa lateral yang digunakan adalah pipa PVC memiliki panjang $100 \mathrm{~cm}$ dengan ukuran $1 / 2$ inci dan terhubung dengan 12 emitter (G) yaitu emitter 1 (G1) hingga emitter 12 (G12). Selang emitter $(\mathrm{G})$ yang digunakan pada penelitian ini adalah selang PE dengan ukuran $5 \mathrm{~mm}$. Emitter (G) berfungsi meyalurkan air dari pipa lateral ke tanah sekitar tanaman secara kontinu dengan debit yang rendah. Jarak antara emitter satu dengan yang lainnya pada baris yang sama adalah $40 \mathrm{~cm}$. Sehingga sistem fertigasi tetes yang dibangun dapat digunakan pada lahan dengan ukuran 120 × $200 \mathrm{~cm}^{2}$ untuk 12 tanaman tomat.

\section{Perancangan Sistem Kendali Fertigasi Tetes}

Perancangan sistem kendali pemupukan tanaman meliputi perancangan rangkaian input dan rangkaian output yang akan dikontrol oleh Arduino Uno yang berbasis ATMega328P [9]. Gambar 3 menunjukkan peracangan sistem kendali pemupukan tanaman yang dibangun.

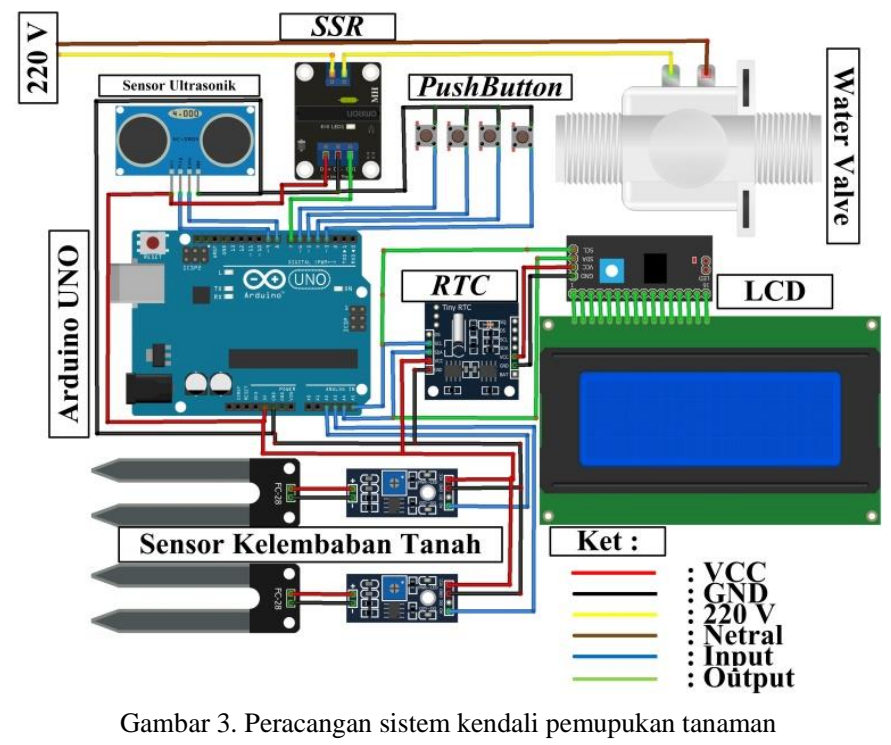

Pengkabelan berwarna biru merupakan pengkabelan antara pin yang digunakan sebagai pin input Arduino dengan komponen input seperti sensor utrasonik, RTC, sensor kelembaban tanah, dan pushbutton.

Sensor ultrasonik merupakan perangkat yang digunakan untuk mengukur jarak dari suatu objek berbasis gelombang ultrasonik sehingga dalam penerapannya dapat digunakan sebagai pengukur jarak larutan pupuk cair dengan air yang berada di dalam tangki, dengan demikian dapat mengetahui ketersedian larutan dalam tangki [10].

Sedangkan RTC digunakan sebagai pewaktu eksternal pada mikrokontroler yang nantinya dapat digunakan sebagai sebagai penentu waktu pemupukan. Sensor kelembaban tanah dimanfaatkan untuk mengukur kelembaban tanah. Sensor ini menggunakan dua buah probe untuk melewatkan arus melalui tanah lalu membaca tingkat resistansinya untuk mendapatkan tingkat kelembaban tanah. Makin banyak air membuat tanah makin mudah mengalirkan arus listrik (resistansi rendah), sebaliknya tanah yang kering sulit mengalirkan arus listrik (resistansi tinggi) [11]. Persamaan (1) digunakan untuk mempermudah pembacaan kelembaban tanah dengan mengubah nilai dalam bentuk persen [12].

$$
\mathrm{Kt}(\%)=\frac{1023-N s}{1023} \times 100 \%
$$

di mana Kt adalah kelembaban tanah $(\%)$ dan $N s$ adalah nilai sensor.

Untuk pengkabelan berwarna hijau merupakan pengkabelan yang menghubungkan antara pin yang digunakan sebagai output seperti SSR dan LCD. SSR merupakan saklar elektronik yang biasa digunakan sebagai device pengendali. Pada penelitian ini SSR berfungsi sebagai pengendali pembukaan/ penutupan saluran pada water valve. Water valve yang digunakan memiliki katup pengalir dan motor pengalir. Selanjutnya katup pengalir memiliki saluran inlet port sebagai saluran masuk dan outlet port sebagai saluran keluar. Inlet port berfungsi sebagai port yang akan dimasuki oleh cairan fertigasi, sementara outlet port berfungsi sebagai port tempat keluarnya cairan tersebut. Water valve bekerja dengan cara mengalirkan arus listrik sehingga katup kran terbuka dan sebaliknya ketika arus listrik diputus maka kran menutup kembali. Sedangkan LCD berfungsi untuk untuk menampilkan data yang dibaca oleh komponen input dan informasi lainnya. 


\section{Debit Emitter}

Penentuan debit emitter sangat diperlukan untuk mengetahui koefsien keseragaman fertigasi tetes dan juga untuk memperkirakan waktu pembukaan pada water valve atau dengan kata lain lamanya waktu diperlukan untuk melakukan pemupukan pada tanaman [13], [14]. Debit emitter dihitung dengan cara membagi antara volume aliran yang tertampung dalam wadah dengan lamanya waktu pengukuran seperti ditunjukkan pada (2).

$$
\mathrm{Q}=\mathrm{V} / \mathrm{t}
$$

di mana $\mathrm{Q}$ adalah debit (liter/jam), $\mathrm{V}$ adalah volume (liter), dan $t$ adalah waktu (jam).

\section{E. Koefisien Keseragaman Fertigasi Tetes}

Untuk menentukan kelayakan dari instalasi fertigasi tetes yang dirancang diperlukan perhitungan keseragaman emitter dengan menggunakan (3) [15].

$$
\mathrm{CU}=100\left\{1-\frac{\sum|x i-x|}{\sum x i}\right\}
$$

di mana CU adalah koefisien keseragaman fertigasi (\%), xi adalah volume air pada wadah ke-i $(\mathrm{ml}), x$ adalah nilai ratarata dari volume air pada wadah $(\mathrm{ml})$, dan $\sum|x i-x|$ adalah jumlah deviasi absolut rata-rata pengukuran $(\mathrm{ml})$.

Evaluasi nilai koefisien keseragaman cairan fertigasi ditunjukkan pada Tabel I di mana semakin besar persentase nilai koefisien keseragaman maka kelasnya semakin baik [16], [17].

TABEL I. KLASIFIKASI NILAI KOEFISIEN KeSERAGAMAN FERTIGASI TETES

\begin{tabular}{cl}
\hline \hline $\begin{array}{c}\text { Nilai Koefisien Keseragaman } \\
\text { Fertigasi Tetes }(\%)\end{array}$ & \multicolumn{1}{c}{ Kelas } \\
\hline$>90$ & Sangat Baik \\
$80-90$ & Baik \\
$70-80$ & Cukup/Sedang \\
$<70$ & Buruk \\
\hline \hline
\end{tabular}

\section{F. Kalibrasi Sensor Kelembaban Tanah}

Untuk mendapatkan dan mengetahui tingkat keakuratan sensor ketika pengambilan data dibutuhkan proses kalibrasi sensor. Proses kalibrasi sensor menggunakan perbandingan antara massa air dengan massa tanah seperti yang ditunjukkan pada (4) [18].

$$
\mathrm{Ka}(\%)=\frac{M a}{M t} \times 100 \%
$$

di mana Ka adalah kadar air (\%), $M a$ adalah massa air $(\mathrm{Kg})$ dan $M t$ adalah massa tanah $(\mathrm{Kg})$. Persamaan (5) digunakan untuk mengetahui massa air.

$$
\mathrm{Ma}=\mathrm{Mtb}-\mathrm{Mtk}
$$

di mana Mtb adalah massa tanah basah (Kg) dan Mtk adalah massa tanah kering $(\mathrm{Kg})$.

\section{HASIL DAN PEMBAHASAN}

\section{A. Pembangunan Sistem Fertigasi Tetes}

Penerapan rancangan pada sub bagian II-B dapat dilihat pada Gambar 4 yang menunjukkan sistem fertigasi tetes yang telah dibangun dan mampu mengalirkan cairan fertigasi dari tangki suplai ke tanaman. Komponen yang digunakan yaitu water valve, pipa PVC $1 / 2$ inci, selang PE $5 \mathrm{~mm}$, dan stick dripper $5 \mathrm{~mm}$ (emitter).

Water valve berfungsi sebagai keran otomatis yang akan membuka dan menutup cairan fertigasi dari tangki ke tanaman. Water valve diletakkan tepat di bawah tangki dan

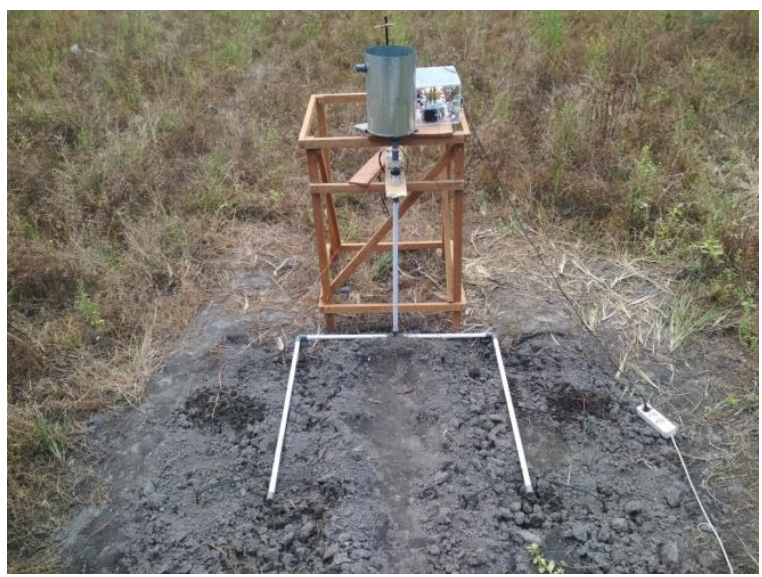

Gambar 4. Sistem fertigasi tetes yang dibangun

terhubung langsung dengan saluran keluaran pada tangki. Water valve ini dikontrol oleh mikrokontroler dalam melakukan pembukaan dan penutupan salurannya.

Pipa utama dipasang dan terhubung langsung dengan water valve yang selanjutnya diteruskan ke bagian pipa manifold dan pipa lateral. Di sepanjang pipa lateral dengan jarak setiap $40 \mathrm{~cm}$ dipasangkan selang-selang PE dengan panjang $30 \mathrm{~cm}$. Pada ujung selang PE dipasangkan stick emitter yang ditancapkan langsung ke tanah di sekitar tanaman.

\section{B. Pembangunan Sistem Kendali Pemupukan Tanaman}

Pada penelitian yang dilakukan oleh [5] komponen pada sistem kendali yang dibangun sebagai indikator melakukan pemupukan sudah cukup lengkap, akan tetapi tidak memiliki komponen yang digunakan sebagai pembaca kelembaban tanah dan juga pendeteksi ketersedian suplai pada tangki. Sensor kelembaban tanah sangat penting digunakan sebagai indikator dalam melakukan pemupukan, sementara itu sensor ultrasonik sangat diperlukan untuk menjamin dan mengetahui ketersediaan cairan di dalam tangki suplai.

Pada penelitian ini komponen elektronika dan beberapa sensor diletakkan di atas papan PCB yang didisain menggunakan aplikasi EAGLE. Setelah disain layout jalur komponen pada aplikasi EAGLE selesai langkah selanjutnya adalah menempelkan hasil layout ke papan PCB, apabila layout sudah menempel pada papan PCB dengan benar maka hal selanjutnya adalah melarutkan papan PCB dengan menggunakan ferric klorida yang telah dicampurkan dengan air agar kandungan tembaga pada papan PCB yang tersisa hanya pada bagian jalur layout yang digunakan sebagai jalur penghubung antar komponen. Apabila proses pelarutan telah selesai maka komponen yang digunakan dapat diletak dan dihubungkan di atas papan PCB. Adapun komponen yang diletakkan pada PCB antara lain RTC, Arduino, port komponen input dan output sebagai port ekstensi pin I/O Arduino ke PCB. PCB yang sudah rapi tersebut lalu diletakkan di dalam panel box dengan komponen pendukung lainnya agar komponen dapat terlindungi dari kerusakan yang disebabkan oleh gangguan fisik seperti air, debu yang berlebihan dan sebagainya. Sementara itu untuk LCD, pushbutton, dan saklar terletak di depan panel box sebagai komunikasi antara pengguna. Untuk komponen elektronika lainnya yang terhubung secara fisik dengan benda lainnya dipasang tepat di dekat benda tersebut, seperti sensor ultrasonik dipasang dekat dengan tangki suplai dan probe sensor kelembaban tanah ditempatkan di dekat tanaman. 


\section{Kinerja Emitter}

Pengujian debit emitter ini bertujuan untuk menentukan lama pembukaan dari water valve yang akan mengalirkan suplai cairan fertigasi dan juga menentukan koefisien keseragaman fertigasi tetes. Sistem fertigasi tetes memberikan cairan fertigasi dari tangki ke tanah di sekitar tanaman dengan cara meneteskan cairan ferigasi menggunakan emitter yang diletakkan di dekat tanaman. Emitter yang digunakan memiliki diameter lubang yang sangat kecil, sehingga diperlukan waktu yang cukup lama untuk menghabiskan cairan fertigasi pada tangki. Dengan demikian agar terlihat jelas karakteristik debit yang dihasilkan emitter diperlukan penentuan waktu yang cukup lama pula untuk melakukan pengujian debit emitter, sehingga pada pengujian ini waktu yang ditentukan adalah 15 menit dan 30 menit dengan menentukan volume pada tangki sebesar $4.800 \mathrm{ml}$. Kemudian pada masing-masing emitter diletakkan gelas ukur dengan tujuan untuk menampung volume cairan fertigasi yang keluar dari emitter yang digunakan. Setelah didapatkan volume cairan fertigasi pada gelas ukur selanjutnya menentukan debit emitter seperti ditunjukkan pada Tabel II.

TABEL II. Pengujian Debit EMitter Dengan WAKtu 15 Menit dan 30 MENIT

\begin{tabular}{|c|c|c|c|c|}
\hline $\begin{array}{r}\text { Waktu } \\
\text { (menit) }\end{array}$ & Emitter & $\begin{array}{c}\text { Volume } \\
\text { (ml) }\end{array}$ & $\begin{array}{c}\text { Debit } \\
\text { (ml/detik) }\end{array}$ & $\begin{array}{c}\text { Debit } \\
\text { Rata- } \\
\text { Rata } \\
\text { (ml/detik) }\end{array}$ \\
\hline \multirow[t]{12}{*}{15} & 1 & 135 & 0,150000 & 0,157593 \\
\hline & 2 & 152 & 0,168889 & \\
\hline & 3 & 137 & 0,152222 & \\
\hline & 4 & 159 & 0,176667 & \\
\hline & 5 & 137 & 0,152222 & \\
\hline & 6 & 137 & 0,152222 & \\
\hline & 7 & 141 & 0,156667 & \\
\hline & 8 & 142 & 0,157778 & \\
\hline & 9 & 138 & 0,153333 & \\
\hline & 10 & 136 & 0,151111 & \\
\hline & 11 & 149 & 0,165556 & \\
\hline & 12 & 139 & 0,154444 & \\
\hline \multirow[t]{12}{*}{30} & 1 & 248 & 0,137778 & 0,143843 \\
\hline & 2 & 288 & 0,160000 & \\
\hline & 3 & 258 & 0,143333 & \\
\hline & 4 & 292 & 0,162222 & \\
\hline & 5 & 252 & 0,140000 & \\
\hline & 6 & 250 & 0,138889 & \\
\hline & 7 & 256 & 0,142222 & \\
\hline & 8 & 262 & 0,145556 & \\
\hline & 9 & 248 & 0,137778 & \\
\hline & 10 & 240 & 0,133333 & \\
\hline & 11 & 264 & 0,146667 & \\
\hline & 12 & 249 & 0,138333 & \\
\hline
\end{tabular}

Terlihat pada Tabel II bahwa debit maksimum pada pengujian 15 menit adalah $159 \mathrm{ml}$ atau setara dengan 0,177 $\mathrm{ml} /$ detik, lalu debit minimum $135 \mathrm{ml}$ dalam 15 menit atau setara dengan $0,150 \mathrm{ml} /$ detik dan debit rata-rata yang didapatkan adalah $0,157 \mathrm{ml} /$ detik.

Sementara itu debit maksimum emitter pada pengujian 30 menit adalah $292 \mathrm{ml}$ dalam 30 menit atau setara dengan 0,162 $\mathrm{ml} /$ detik lalu debit minimum $240 \mathrm{ml}$ dalam 30 menit atau setara dengan $0,133 \mathrm{ml} /$ detik dan debit rata-rata yang didapatkan adalah $0,142 \mathrm{ml} /$ detik.

Dari pengujian dengan waktu 15 menit dan 30 menit dapat dilihat debit pada pengujian 15 menit lebih tinggi dibanding debit pada pengujian 30 menit. Hal ini dikarenakan pengaruh ketinggian (tekanan larutan/cairan) fertigasi dalam tangki. Semakin turun tekanan cairan (cairan fertigasi berkurang), maka debit yang mengalir juga akan semakin berkurang.

\section{Koefisien Keseragaman Fertigasi Tetes}

Koefisien keseragaman fertigasi tetes merupakan penentu bagi kelayakan dari instalasi fertigasi tetes yang telah dirancang. Pada penelitian [4] didapatkan hasil koefisien irigasi tetes yang dibangun sebesar $76,97 \%$. Sementara itu pada penelitian [19] didapatkan koefisien irigasi tetes yang dibangun yaitu $71 \%$. Kedua penelitian tersebut mendapatkan klasifikasi nilai koefisien irigasi tetes dengan kelas cukup. Sehingga pada penelitian ini perlu diketahui nilai koefisien keseragaman fertigasi tetes yang dibangun, agar mengetahui apakah cairan fertigasi yang disalurkan dapat terbagi sama rata pada setiap tanaman. Untuk menentukan koefisien keseragaman fertigasi tetes pada pengujian 15 menit ditunjukkan pada Tabel III.

Dari Tabel III didapatkan koefisien keseragaman fertigasi pada perancangan dan instalasi fertigasi tetes yang dibangun adalah 95,9\%. Dari Tabel III maka dapat disimpulkan bahwa fertigasi tetes yang dibangun dan diuji pada pengujian dengan waktu 15 menit ini memiliki efisiensi yang sangat baik dengan koefisien keseragaman fertigasi berada di atas $90 \%$. Dengan metode yang sama, untuk koefisien keseragaman fertigasi tetes pada pengujian 30 menit didapatkan koefisien keseragaman fertigasi pada perancangan dan instalasi fertigasi tetes yang dibangun sebesar 95,5\%.

TABEL III. KOEFISIEN KeSERAGAMAN FERTIGASI TETES DENGAN WAKTU 15 MENIT

\begin{tabular}{cccc}
\hline \hline Emitter & $\begin{array}{c}\text { Debit } \\
\text { (ml/detik) }\end{array}$ & $|\mathbf{x i}-\overline{\boldsymbol{x}}|$ \\
\hline 1 & 0,150000 & 0,007593 \\
2 & 0,168889 & 0,011296 \\
3 & 0,152222 & 0,005370 \\
4 & 0,176667 & 0,019074 \\
& 5 & 0,152222 & 0,005370 \\
6 & 0,152222 & 0,005370 \\
& 7 & 0,156667 & 0,000926 \\
& 8 & 0,157778 & 0,000185 \\
& 9 & 0,153333 & 0,004259 \\
& 10 & 0,151111 & 0,006481 \\
& 11 & 0,165556 & 0,007963 \\
Rumlah & 12 & 0,154444 & 0,003148 \\
Koefisien keseragaman fertigasi $(\%)$ & 95,926361 \\
\hline \hline
\end{tabular}

E. Kinerja Sensor Ultrasonik dan Kelembaban Tanah

Pengujian sensor ultrasonik bertujuan untuk menentukan tinggi air yang berada pada tangki suplai untuk memberi informasi ke pengguna mengenai ketersediaan suplai di dalam tangki suplai yang digunakan untuk menyiram tanaman. Pengujian ini dilakukan dengan mengukur tinggi cairan fertigasi di dalam tangki menggunakan mistar, kemudian dibandingkan dengan pembacaan tinggi cairan fertigasi di dalam tangki oleh sensor ultrasonik. Pada pengujian ini pemberian suplai ke tanaman tomat diperlukan suplai sekitar $300 \mathrm{ml}$ sampai $400 \mathrm{ml}$ untuk tiap tanaman. Karena pada pengujian ini menggunakan 12 emitter (untuk 12 tanaman tomat) maka dibutuhkan sekitar 3.600-4.800 ml cairan fertigasi yang harus tersedia di dalam tangki suplai. Tabel IV menunjukkan data pengujian tinggi cairan fertigasi yang dibaca oleh sensor ultrasonik. 
Terlihat pada Tabel IV bahwa sensor ultrasonik memberikan akurasi yang sangat tinggi di mana kesalahan adalah $0 \%$, hal ini telah dicantumkan pada data sheet sensor ultrasonik yang digunakan bahwa akurasi sensor ultrasonik yang digunakan sangat baik ketika pada jarak ukur $2 \mathrm{~cm}$ hingga $400 \mathrm{~cm}$ tepat dari depan sensor. Keakuratan pembacaan sensor ultrasonik ini memberikan pengaruh untuk tanaman yaitu agar suplai cairan fertigasi yang akan disalurkan ketanaman tercukupi sesuai kebutuhan yang telah dihitung.

Pengujian sensor kelembaban tanah bertujuan agar sensor memberikan hasil pengukuran kelembaban yang tepat. Kelembaban tanah yang baik untuk tanaman tomat yaitu antara $60-80 \%$ [20]. Hasil pengujian sensor kelembaban ditunjukkan pada Tabel V dan Tabel VI.

Tabel V menunjukkan hasil pengujian sensor kelembaban tanah 1. Masa tanah kering didapatkan dengan cara mengeringkan tanah pada oven yang telah diatur pada suhu 100-110 ${ }^{0} \mathrm{C}$. Kemudian massa tanah yang telah dioven tersebut ditimbang. Sementara itu untuk masa tanah basah adalah penjumlahan masa tanah kering ditambah dengan masa air. Untuk ASM merupakan nilai hasil kelembaban tanah yang didapatkan dengan menggunakan (4) dan (5) sesuai dengan metode yang dijelaskan pada [18]. Tabel V menunjukkan kesalahan rata-rata sebesar 1,6\% dengan demikian sensor yang digunakan memiliki keakuratan yang tinggi.

Tabel VI menunjukkan hasil pengujian sensor kelembaban tanah 2 dengan nilai kesalahan rata-rata 1\% dengan tingkat kesalahan terbesar adalah 2\%. Dengan demikian kedua sensor kelembaban tanah 1 dan sensor kelembaban tanah 2 yang digunakan bekerja dengan sangat baik. Dengan demikian target untuk mendapatkan kelembaban tanah di sekitar tanaman tomat sebesar 60-80\% dapat dicapai.

TABEL IV. PENGUJIAN SENSOR ULTRASONIK

\begin{tabular}{|c|c|c|c|}
\hline $\begin{array}{l}\text { Tinggi } \\
\text { Suplai } \\
\text { (cm) }\end{array}$ & $\begin{array}{c}\text { Pembacaan } \\
\text { Sensor } \\
\text { Ultrasonik }(\mathrm{cm})\end{array}$ & $\begin{array}{c}\text { Kesalahan } \\
(\%)\end{array}$ & Keterangan \\
\hline 1 & 1 & 0 & Suplai Habis \\
\hline 2 & 2 & 0 & Suplai Habis \\
\hline 3 & 3 & 0 & Suplai Habis \\
\hline 4 & 4 & 0 & Suplai Habis \\
\hline 5 & 5 & 0 & Suplai Habis \\
\hline 6 & 6 & 0 & Suplai Habis \\
\hline 7 & 7 & 0 & Suplai Habis \\
\hline 8 & 8 & 0 & Suplai Habis \\
\hline 9 & 9 & 0 & Suplai Habis \\
\hline 10 & 10 & 0 & Suplai Habis \\
\hline 11 & 11 & 0 & Suplai Tersedia \\
\hline 12 & 12 & 0 & Suplai Tersedia \\
\hline 13 & 13 & 0 & Suplai Tersedia \\
\hline 14 & 14 & 0 & Suplai Tersedia \\
\hline 15 & 15 & 0 & Suplai Tersedia \\
\hline 16 & 16 & 0 & Suplai Tersedia \\
\hline 17 & 17 & 0 & Suplai Tersedia \\
\hline 18 & 18 & 0 & Suplai Tersedia \\
\hline 19 & 19 & 0 & Suplai Tersedia \\
\hline 20 & 20 & 0 & Suplai Tersedia \\
\hline 21 & 21 & 0 & Suplai Tersedia \\
\hline 22 & 22 & 0 & Suplai Tersedia \\
\hline 23 & 23 & 0 & Suplai Tersedia \\
\hline 24 & 24 & 0 & Suplai Tersedia \\
\hline 25 & 25 & 0 & Suplai Tersedia \\
\hline
\end{tabular}

TABel V. Pengujian Kesalahan Sensor Kelembaban Tanah 1

\begin{tabular}{|c|c|c|c|c|}
\hline \multirow{2}{*}{$\begin{array}{c}\text { Massa Tanah } \\
\text { Kering } \\
(\mathrm{Kg})\end{array}$} & \multirow{2}{*}{$\begin{array}{c}\text { Massa Tanah } \\
\text { Basah } \\
(\mathrm{Kg})\end{array}$} & \multicolumn{2}{|c|}{ Kelembaban Tanah (\%) } & \multirow{2}{*}{$\begin{array}{c}\text { Perbedaan Hasi } \\
\text { Pengukuran } \\
(\%)\end{array}$} \\
\hline & & $\begin{array}{c}\text { American Standard } \\
\text { Methode (ASM) }\end{array}$ & $\begin{array}{c}\text { Sensor Kelembaban } \\
\text { Tanah }\end{array}$ & \\
\hline 0,1 & 0,11 & 10 & 11 & 1,0 \\
\hline 0,1 & 0,12 & 20 & 22 & 2,0 \\
\hline 0,1 & 0,13 & 30 & 31 & 1,0 \\
\hline 0,1 & 0,14 & 40 & 41 & 1,0 \\
\hline 0,1 & 0,15 & 50 & 52 & 2,0 \\
\hline 0,1 & 0,16 & 60 & 63 & 3,0 \\
\hline 0,1 & 0,17 & 70 & 72 & 2,0 \\
\hline 0,1 & 0,18 & 80 & 79 & 1,0 \\
\hline 0,1 & 0,19 & 90 & 89 & 1,0 \\
\hline 0,1 & 0,20 & 100 & 98 & 2,0 \\
\hline \multicolumn{4}{|c|}{ Kesalahan rata-rata $(\%)$} & 1,6 \\
\hline
\end{tabular}

TABEL VI. Pengujian Kesalahan SEnSOR Kelembaban TANah 2

\begin{tabular}{|c|c|c|c|c|}
\hline \multirow{2}{*}{$\begin{array}{c}\text { Massa Tanah } \\
\text { Kering } \\
(\mathrm{Kg})\end{array}$} & \multirow{2}{*}{$\begin{array}{c}\text { Massa Tanah } \\
\text { Basah } \\
(\mathrm{Kg})\end{array}$} & \multicolumn{2}{|c|}{ Kelembaban Tanah $(\%)$} & \multirow{2}{*}{$\begin{array}{c}\text { Perbedaan Hasil } \\
\text { Pengukuran } \\
(\%)\end{array}$} \\
\hline & & $\begin{array}{c}\text { American Standard } \\
\text { Methode (ASM) }\end{array}$ & $\begin{array}{c}\text { Sensor Kelembaban } \\
\text { Tanah }\end{array}$ & \\
\hline 0,1 & 0,11 & 10 & 11 & 1 \\
\hline 0,1 & 0,12 & 20 & 21 & 1 \\
\hline 0,1 & 0,13 & 30 & 31 & 1 \\
\hline 0,1 & 0,14 & 40 & 42 & 2 \\
\hline 0,1 & 0,15 & 50 & 52 & 2 \\
\hline 0,1 & 0,16 & 60 & 60 & 0 \\
\hline 0,1 & 0,17 & 70 & 71 & 1 \\
\hline 0,1 & 0,18 & 80 & 82 & 2 \\
\hline 0,1 & 0,19 & 90 & 90 & 0 \\
\hline 0,1 & 0,20 & 100 & 100 & 0 \\
\hline \multicolumn{4}{|c|}{ Kesalahan rata-rata $(\%)$} & 1 \\
\hline
\end{tabular}




\section{F. Pengujian Sistem Kendali Fertigasi Tanaman}

Pengujian alat sistem kendali fertigasi ini dilakukan dalam beberapa langkah. Pertama, alat diletakkan pada sebuah lahan kosong dengan area yang dapat ditanami tanaman tomat. Proses selanjutnya adalah melakukan perakitan sistem distribusi perpipaan dan menancapkan emitter pada tanah yang akan ditanami tanaman seperti yang ditunjukkan pada Gambar 4 pada sub bagian sebelumnya. Saat sistem kendali berbasis arduino diaktifkan maka pada LCD akan ditampilkan data yang dibaca oleh sensor seperti yang ditunjukkan Gambar 5 seperti ketersediaan pupuk yang dibaca oleh sensor ultrasonik, tanggal, jam dan hari yang dibaca oleh RTC, dan kelembaban tanah yang dibaca oleh sensor kelembaban tanah.

Arduino akan memproses penghitungan hari. Pupuk cair yang digunakan adalah EM-4 di mana pemupukan tomat dilakukan sekali dalam 14 hari. Ketika mencapai hitungan 14 hari, selanjutnya Arduino memerintahkan untuk melakukan pemupukan dengan cara membukan e-valve. Pada sistem juga diatur agar waktu pemupukan dilakukan sebelum jam 10 pagi atau sesudah jam 3 siang dan akan menampilkan tampilan "Hari Ke-14, Hari Pemupukan" pada LCD.

Ketika sudah tepat pada pukul yang ditentukan, Arduino melakukan pengecekan lagi terhadap kelembaban tanah melalui pembacaan sensor kelembaban tanah, di mana kelembaban tanah yang baik untuk tomat berada diantara 60$80 \%$. Sehingga untuk menjaga agar kelembaban tanah tidak lebih dari $80 \%$ dan agar cairan fertigasi dapat disalurkan seluruhnya. Pada saat berlangsungnya proses pemupukan tersebut sistem tetap secara kontinyu melakukan pembacaan ketersediaan cairan fertigasi dalam tangki agar proses pemupukan dapat berjalan dengan sempurna.

Pada penelitian ini cairan fertigasi berasal dari campuran antara 3.600 sampai dengan $4.800 \mathrm{ml}$ air dengan 36 sampai dengan $48 \mathrm{ml}$ pupuk cair EM-4, dengan spesifikasi tabung dengan diameter $21 \mathrm{~cm}$ dan dengan jarak dari permukaan tabung dengan sensor ultrasonik yaitu $38 \mathrm{~cm}$. Dengan demikian, tinggi cairan fertigasi berada di tabung harus tersedia dengan jarak dari permukaan tabung dengan tinggi besar dari atau sama dengan $11 \mathrm{~cm}$.

Ketika ketinggian cairan fertigasi dalam tangki terbaca lebih besar $11 \mathrm{~cm}$ yang berarti suplai tersedia, maka selanjutnya Arduino memberikan perintah ke SSR agar aktif sehingga motor penggerak pada water valve mendapat suplai tegangan dan membuka valve hingga cairan fertigasi dapat mengalir dari tangki suplai hingga menetes melalui emitter ke tanah sekitar tanaman. Pada saat kondisi ini Arduino akan menampilkan tampilan "Sedang Melakukan Pemupukan Harap Tunggu, Estimasi 45 Menit" pada LCD. Akan tetapi apabila sensor ultrasonik membaca ketinggian cairan fertigasi di bawah $11 \mathrm{~cm}$, maka LCD akan menampilkan tampilan "Suplai habis silahkan isi cairan fertigasi".

Water valve terus membuka hingga sensor kelembaban tanah membaca kelembaban tanah di sekitar tanaman dengan

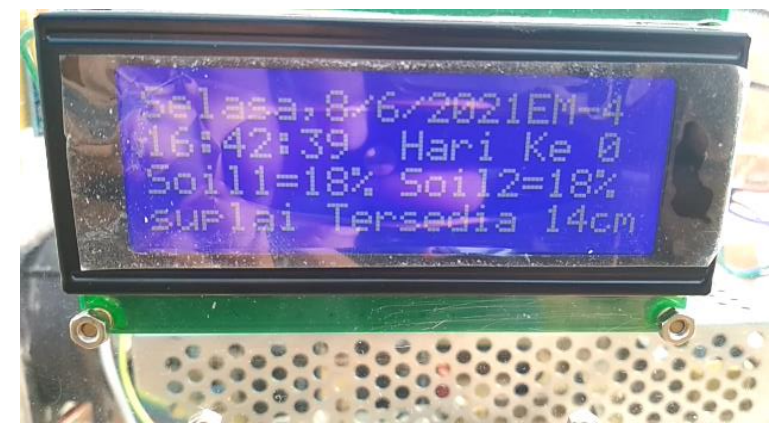

Gambar 5. Data yang ditampilkan LCD

nilai 80\%. Namun apabila selama 45 menit kelembaban tanah di sekitar tanaman tidak terpenuhi nilainya sebesar $80 \%$, maka water valve akan menutup secara otomatis dikarenakan selama 45 menit dapat dipastikan cairan fertigasi di dalam tangki telah habis tersuplai ke seluruh tanaman. Selanjutnya setelah water valve menutup kembali, sistem akan kembali menampilkan data awal yaitu antara lain ketersediaan pupuk, tanggal, jam, hari, kelembaban tanah.

Sementara itu untuk hasil dari pembacaan sensor kelembaban tanah dan sensor ultrasonik pada saat dilakukannya pengujian sistem secara keseluruhan ditunjukkan pada Tabel VII. Berdasarkan Tabel VII didapatkan sistem bekerja pada jam 16.45 yaitu ketika sensor kelembaban tanah telah membaca kelembaban tanah berada pada kondisi di bawah $25 \%$ sehingga Arduino memberikan perintah untuk segera melakukan pemupukan dengan membuka water valve yang digunakan sebagai kran otomatis. Sementara itu untuk pembacaan sensor kelembaban tanah hanya terjadi perbedaan pembacaan yang sangat sedikit dan dapat ditoleransi, hal ini dikarenakan perbedaan debit emitter sehingga volume cairan fertigasi yang tersampaikan pada tanah disetiap emitter terjadi perbedaan. Akan tetapi dapat dikatakan antara sensor kelembaban tanah satu dengan yang lainnya bekerja secara sinkron.

Sensor ultrasonik yang digunakan dapat membaca ketersediaan cairan fertigasi pada tangki dengan baik. Pada awal sebelum melakukan pemupukan, sensor membaca ketinggian air $14 \mathrm{~cm}$ sesuai dengan kondisi nyata. Setelah selesai melakukan pemupukan, sensor ultrasonik yang digunakan membaca ketinggian cairan fertigasi $0 \mathrm{~cm}$ yang menandakan pemupukan telah selesai, dan cairan fertigasi pada tangki telah habis tersalurkan ke tanah di sekitar tanaman.

Water valve yang digunakan bekerja selama kurang lebih 45 menit membuka aliran sesuai dengan perkiraan estimasi yang dilakukan dengan cara menguji dan menghitung debit pada emitter. Dari hasil pengujian yang telah dilakukan menunjukkan bahwa sistem fertigasi yang telah dibangun berhasil menyalurkan cairan fertigasi ke tanaman tepat pada waktu dilakukannya pemupukan, dan juga menampilkan data yang dibutuhkan sebagai interaksi kepada pengguna.

TABEL VII. PENGUJian KesEluruhan Sistem

\begin{tabular}{|c|c|c|c|c|c|c|}
\hline \multirow{2}{*}{ No } & \multirow{2}{*}{$\begin{array}{l}\text { Waktu } \\
\text { (WIB) }\end{array}$} & \multicolumn{2}{|c|}{ Sensor Kelembaban Tanah (\%) } & \multirow{2}{*}{ Sensor Ultrasonik (cm) } & \multirow{2}{*}{ Keterangan } & \multirow{2}{*}{ Water Valve } \\
\hline & & Sensor 1 & Sensor 2 & & & \\
\hline 1 & 16.30 & 29 & 29 & 14 & Suplai Tersedia & Menutup \\
\hline 2 & 16.45 & 24 & 23 & 14 & Suplai Tersedia & Membuka \\
\hline 3 & 17.00 & 49 & 49 & 9 & Sedang Melakukan Pemupukan & Membuka \\
\hline 4 & 17.15 & 64 & 63 & 5 & Sedang Melakukan Pemupukan & Membuka \\
\hline 5 & 17.30 & 74 & 75 & 0 & Suplai Habis & Menutup \\
\hline 6 & 17.45 & 72 & 72 & 0 & Suplai Habis & Menutup \\
\hline
\end{tabular}




\section{IV.PENUTUP}

Berdasarkan penelitian yang telah dilakukan tentang sistem fertigasi tetes bagi tanaman berbasis mikrokontroler dapat disimpulkan bahwa pengujian alat pada sistem kendali pendistribusian cairan fertigasi pada tanaman yang dibangun bekerja sesuai dengan rancangan yang dibuat. Keberhasilan ini ditunjukkan dengan didapatkannya kesalahan pada sensor yang digunakan tidak melebihi $1,6 \%$. Keseragaman fertigasi tetes yang dihasilkan lebih besar dari $90 \%$ sebagai indikasi efisiensi keseragaman tetesan yang sangat baik. Otomastisasi sistem fertigasi yang dibangun dalam melakukan fertigasi untuk tanaman tomat dapat dilakukan secara otomatis dalam waktu 14 hari sekali. Dikarenakan penggunaan daya yang relatif kecil dan agar mempermudah dalam melakukan suplai daya listrik untuk komponen elektronika yang digunakan maka penelitian selanjutnya dapat menggunakan suplai dengan menggunakan Pembangkit Listrik Tenaga Surya (PLTS).

\section{REFERENSI}

[1] R. de S. Bezerra, A. W. P. Evangelista, L. M. Vellame, J. A. Júnior, and D. Casaroli, "Low-cost automation of fertigation with programmable logic controller and gas-filled sensors," Eng. Agric., vol. 37, no. 2, pp. 394-402, 2017.

[2] H. Wang et al., "Optimal drip fertigation management improves yield, quality, water and nitrogen use efficiency of greenhouse cucumber," Sci. Hortic., vol. 243, pp. 357-366, 2019.

[3] J. Hu et al., "Drip fertigation promotes water and nitrogen use efficiency and yield stability through improved root growth for tomatoes in plastic greenhouse production," Agric. Ecosyst. Environ. vol. 313, pp. 1-9, 2021.

[4] E. G. Ekaputra, D. Yanti, D. Saputra, and F. Irsyad, "Rancang Bangun Sistem Irigasi Tetes untuk Budidaya Cabai (Capsicum Annum L.) dalam Greenhouse di Nagari Biaro, Kecamatan Ampek Angkek, Kabupaten Agam, Sumatera Barat" J. Irig., vol. 11, no. 2, pp. 103 112, 2016.

[5] A. Fajar, S. H Abdullah, and A. Priyati, "Rancang Bangun Dan Uji Kinerja Sistem Kontrol Fertigasi Dengan Irigasi Tetes," J. Agrotek UMMAT, vol. 5, no. 1, pp. 19-29, 2018.

[6] B. Lanya, P. A. Laksono, M. Amin, and R. Zahab, "Rancang bangun sistem fertigasi dengan menggunakan venturimeter," J. Tek. Pertan. Lampung, vol. 9, no. 2, pp. 122-130, 2020.
[7] S. Sirait and S. Maryati, "Sistem Kontrol Irigasi Sprinkler Otomatis Bertenaga Surya di Kelompok Tani Kecamatan Meureubo Kabupaten Aceh Barat," J. Irig., vol. 13, no. 1, pp. 55-66, 2018.

[8] E. Maulana and M. Idrus, "Pengaruh interval waktu pemberian air terhadap produktivitas tanaman tomat di lahan kering dataran rendah pada musim kemarau," J. Penelit. Pertan. Terap., vol. 10, no. 3, pp. 207-212, 2010

[9] R. H. Sudhan, M. G. Kumar, A. U. Prakash, S. A. R. Devi, and P. Sathiya, "Arduino atmega-328 microcontroller," IJIREEICE, vol. 3, no. 4, pp. 27-29, 2015.

[10] F. Puspasari, I. Fahrurrozi, T. P. Satya, G. Setyawan, M. R. Al Fauzan, and E. M. D. Admoko, "Sensor ultrasonik HCSR04 berbasis arduino due untuk sistem monitoring ketinggian," J. Fis. dan Apl., vol. 15, no. 2, pp. 36-39, 2019.

[11] D. Rahmawati, F. Herawati, G. Saputra, and Hendro, "Karakterisasi sensor kelembaban tanah (YL-69) untuk otomatisasi penyiraman tanaman berbasis arduino uno," Pros. SKF 2017, pp. 92-97, 2017.

[12] C. P. Yahwe, Isnawaty, and L. F. Aksara, "Rancang bangun prototype system monitoring kelembaban tanah melalui SMS berdasarkan hasil penyiraman tanaman studi kasus tanaman cabai dan tomat," semanTIK vol. 2, no. 1, pp. 97-110, 2016.

[13] E. Nazari, S. Besharat, K. Zeinalzadeh, and A. Mohammadi, "Measurement and simulation of the water flow and root uptake in soil under subsurface drip irrigation of apple tree," Agric. Water Manag., vol. 255, p. 106972, 2021.

[14] T. Muhammad, B. Zhou, Z. Liu, X. Chen, and Y. Li, "Effects of phosphorus-fertigation on emitter clogging in drip irrigation system with saline water," Agric. Water Manag., vol. 243, p. 106392, 2021.

[15] Z. Liu et al., "Influence of operating pressure on emitter anti-clogging performance of drip irrigation system with high-sediment water," Agric. Water Manag., vol. 213, pp. 174-184, 2019.

[16] A. Selvaperumal, E. Sujitha, and I. Muthuchamy, "Evaluation of uniformity coefficient and soil moisture distribution under drip irrigation system," Curr. J. Appl. Sci. Technol., vol. 34, no. 5, pp. 1-9, 2019.

[17] H. M. Al-Ghobari, "A comparison of water application uniformity for drip irrigation system above and below soil surface at various soil depths and scheduling techniques in arid region," WIT Trans. Ecol. Environ., vol. 168, pp. 311-322, 2012.

[18] ASTM D2216-19, "Standard test methods for laboratory determination of water (moisture) content of soil and rock by mass," ASTM, 2019.

[19] R. Amalia, R. S. B. Waspodo, and B. I. Setiawan, "Rancangan sistem irigasi evaporatif untuk tanaman lada," J. Irig., vol. 15 , no. 1, pp. 45 $54,2020$.

[20] R. Gunawan, T. Andhika, Sandi, and F. Hibatulloh, "Monitoring system for soil moisture, temperature, $\mathrm{pH}$ and automatic watering of tomato plants based on internet of things," Telekontran J. Ilm. Telekomun. Kendali dan Elektron. Terap., vol. 7, no. 1, pp. 66-78, 2019. 